\title{
An Evaluation Model of the Learning Effect of Physical Education Major Courses in Colleges
}

\author{
https://doi.org/10.3991/ijet.v15i07.13691 \\ Shimin Tong \\ Chongqing Technology and Business University, Chongqing, China \\ 619875667@qq.com
}

\begin{abstract}
There are several problems with the evaluation of the learning effect of physical education (PE) major courses in colleges, namely, the diversity of constraints and the lack of multiple perspectives. To solve the problems, this paper puts forward a novel model to evaluate the said learning effect. First$1 y$, the authors identified the problems and principles of learning effect evaluation of PE major courses in colleges, and established an evaluation index system from the perspectives of teachers and students. On this basis, an effective evaluation algorithm was developed to quantify the learning effect through gray clustering analysis. The proposed evaluation model can accurately assess the learning effect of PE major courses. The research findings enjoy great significance in theoretical innovation and engineering application.
\end{abstract}

Keywords - Physical education (PE), colleges, evaluation system, evaluation algorithm

\section{Introduction}

Physical education (PE) is an essential part of higher education. High-quality PE helps college students develop in an all-round way [1-3]. Currently, various modern techniques and concepts have been applied to higher education, reshaping the contents, forms, means and modes of PE in colleges [4-6].

Many scholars have explored deep into the implementation of PE in colleges. For instance, Kwon \& Block [7] discussed how to educate PE teachers with the adapted PE e-learning program. Egan et al. [8] carried out a case study of a health-friendly PE program, which covers various physical activities in school. Packham \& Street [9] investigated the effects of PE on student fitness, achievement and behavior. Heemskerk et al. [10] analyzed how the intensity and cognitive demand of PE courses on subsequent learning. The above studies mainly focus on strategic analysis, failing to evaluate the learning effect of PE major courses in colleges. To improve subsequent learning of PE, the learning effect of the said courses must be evaluated in a systematic and reasonable manner, and the weaknesses of PE in colleges must be identified and solved, making PE in colleges more efficient and effective.

It is a complex and systematic task of decision-making to evaluate the learning effect of PE major courses in colleges. Many kinds of influencing factors must be pro- 
cessed before making the correct decisions [11-12]. The traditional methods for systematic decision-making include analytic hierarchy process (AHP) [13-14], decision tree [15-16], Bayesian method [17-18] and Markov model [19-20]. However, these traditional methods only apply to specific scopes, and have limitations in fuzzy decision-making.

Drawing on multiple intelligence theory and grey correlation theory [21-27], this paper probes deep into the evaluation system for the learning effect of PE major courses in colleges, and established an effective gray clustering evaluation algorithm to evaluate the said effect.

The remainder of this paper is organized as follows: Section 2 enumerates the problems and principles of the learning effect evaluation of PE major courses in colleges; Section 3 sets up an evaluation system for the said learning effect from multiple perspectives; Section 4 designs and implements an evaluation algorithm for the said learning effect; Section 5 puts forward the research conclusions.

\section{Preliminaries}

\subsection{Existing problems}

In higher education, the PE is an important means to implement quality education. More and more departments and majors have opened PE major courses. Meanwhile, a growing attention has been paid to the learning effect of PE major courses and its evaluation. However, it is very difficult to implement the existing evaluation methods, because various problems have emerged in the evaluation process. The current problems mainly fall into five categories:

- First, there is no unified implementation standard for PE among colleges. Each college has its own way to open and teach PE major courses. Thus, the evaluation standard of learning effect must be diversified.

- Second, the modes and contents of PE major courses vary from college to college, owing to the different understandings of the role of PE in higher education. Each college administrator looks at the learning effect from a unique perspective.

- Third, the current evaluation systems mostly focus on one or a few indices, rather than evaluate the learning effect comprehensively from multiple levels. In other words, there is not yet an organic and comprehensive evaluation system.

- Fourth, many colleges lag behind the times in the modes, methods, means and contents of PE, failing to introduce emerging techniques into the teaching process. Therefore, the learning effect evaluation is generally outdated and static.

- Fifth, the indices are not scientific and rational enough in the evaluation models for the learning effect. These models cannot demonstrate the objectives of PE major, the requirements of quality education, integration between the theories and practices in PE. There is ample room to improve the effectiveness, accuracy and reliability of the current models. 


\subsection{Evaluation principles}

To make the evaluation more effective and feasible, the above problems can be resolved by the following principles:

\section{Diversification:}

Traditionally, the learning effect of PE major courses in colleges is evaluated by a single subject or from only one perspective. The evaluation model lacks clarity and adaptiveness. The evaluation results often deviate from the actual situation.

To solve the problem, multiple perspectives should be introduced to diversify the evaluation process. Besides learning, the relevant links like teaching should be taken into account. In addition to PE classes, such environments as extracurricular activities should be considered.

Moreover, the evaluation contents ought to be diversified. To reflect the requirements of quality education, the evaluation model should not only consider the contents taught in PE classes, but also the PE contents relevant to quality education. The multiple intelligence theory should be adopted to improve the current model.

Finally, the evaluation subjects must also be diversified. It is improper to evaluate the learning effect by a single subject. Instead, many other subjects, namely, college administrators, PE teachers, students and social organizations, should be involved to output holistic and consistent results.

\section{Contemporaneity:}

The objectives and emphases of higher education change constantly with the times. Higher education has been evolving dynamically, carrying contemporary features. At present, the main objective of higher education has changed from helping students to pass exams to enhancing their overall quality. The PE major courses are opened to advance the quality education of college students.

Against this backdrop, the evaluation model should adapt to the current situation of higher education: the pursuit of quality education. The following aspects should be covered in the evaluation: individualized teaching, teaching reform, integration between theories and practices, and expansion of teaching methods/means.

\section{Scientificity:}

The learning effect of PE major courses in colleges must be evaluated in a scientific manner. The scientificity is a generalized concept, rather than the scientific nature of logic and systemic evaluation indices. In addition to clear scientific meanings, the evaluation indices should be objective, comprehensive, pertinent and effective.

To ensure their objectivity, the evaluation indices must be selected from the actual situation of PE in colleges, revealing the nature of learning effect. Next, the indices should be chosen in the light of comprehensiveness, ensuring the consistency of evaluation results. The pertinence of the evaluation indices cannot be achieved simply by listing all types of indices. The exhaustion method would create many redundant indices, suppressing the evaluation accuracy. Instead, the indices should be selected from multiple angles, considering the evaluation objectives. Finally, the selected indices should quantify the learning effect in an effective manner, and generate correct and reliable results. 


\section{Evaluation System}

Under the above principles, this paper attempts to construct a novel evaluation system for the learning effect of PE major courses in colleges from multiple perspectives. There are two types of subjects in the system: the teaching subjects and the learning subjects. Thus, evaluation system can be split into two parts: the teacher-based subsystem and the learner-based subsystem.

\subsection{Teacher-based subsystem}

The teacher-based subsystem evaluates the learning effect from the perspectives of administrators and PE teachers in colleges. Based on multiple intelligence theory, these subjects examine the impacts of the following factors of PE major on PE education and student learning: resource provision, curriculum planning, classroom teaching, practical teaching, and teaching reform.

Among them, resource provision reflects the quality of software/hardware and the ability of faculty/staff in PE major; curriculum planning manifests the logic and systemic level of PE major courses; classroom teaching demonstrates how well the basic knowledge of PE major is imparted to students; practical teaching measures the integration between classroom knowledge and practical training; teaching reform reveals the innovation ability in PE. The teacher-based subsystem (Table 1) was established based on these factors.

Table 1. Teacher-based subsystem

\begin{tabular}{|c|c|c|}
\hline Criterion layer & Index layer & Meaning \\
\hline \multirow{3}{*}{ Resource provision } & Software/hardware quality & \multirow{3}{*}{$\begin{array}{l}\text { The promoting effects on education quality and } \\
\text { learning effect }\end{array}$} \\
\hline & Teacher ability & \\
\hline & Administrator ability & \\
\hline \multirow{3}{*}{ Curriculum planning } & Rationality of major courses & \multirow{3}{*}{$\begin{array}{l}\text { The promoting effects on musical rhythmic and } \\
\text { logical intelligences }\end{array}$} \\
\hline & Progress control & \\
\hline & Teaching contents & \\
\hline \multirow{4}{*}{ Classroom teaching } & Teaching method & \multirow{4}{*}{$\begin{array}{l}\text { The promoting effects on linguistic, musical } \\
\text { rhythmic, logical, spatial and bodily intelligences }\end{array}$} \\
\hline & Teaching means & \\
\hline & Teaching attitude & \\
\hline & Professional skills & \\
\hline \multirow{5}{*}{ Practical learning } & Innovation ability & \multirow{5}{*}{$\begin{array}{l}\text { The promoting effects on musical rhythmic, } \\
\text { logical, spatial, bodily, intrapersonal and inter- } \\
\text { personal intelligences }\end{array}$} \\
\hline & Thinking ability & \\
\hline & Social service & \\
\hline & Theory-practice integration & \\
\hline & Coordination & \\
\hline \multirow{3}{*}{ Teaching reform } & Reform ability & \multirow{3}{*}{$\begin{array}{l}\text { The promoting effects on logical, intrapersonal, } \\
\text { interpersonal and naturalist intelligences }\end{array}$} \\
\hline & PE participation & \\
\hline & Theory implementation & \\
\hline
\end{tabular}




\subsection{Student-based subsystem}

The student-based subsystem evaluates the learning effect from the perspectives of PE majors in colleges. Based on multiple intelligence theory, the learning effect of PE major courses was evaluated by the following abilities of PE majors: digestive ability, creativity, practical ability and output.

Specifically, digestive ability reflects the digestion of knowledge before, during and after class, and how the digestion affects the learning effect; creativity measures the innovation and development of students in the course of PE, and how these elements affect the learning effect; practical ability demonstrates how well the students integrates theories and practices and how the integration affects the learning effect; output refers to the performance of the students after receiving the PE major courses. The student-based subsystem (Table 2) was established based on these factors.

Table 2. Student-based subsystem

\begin{tabular}{|c|c|c|}
\hline Criterion layer & Index layer & Meaning \\
\hline \multirow{5}{*}{ Digestive ability } & Digestion of basic knowledge & \multirow{5}{*}{$\begin{array}{l}\text { The effects on linguistic, musical rhythmic, } \\
\text { logical, and naturalist intelligences }\end{array}$} \\
\hline & Acceptance of professional moves & \\
\hline & Acquisition of professional skills & \\
\hline & Correctness of learning attitude & \\
\hline & Dedication to learning & \\
\hline \multirow{3}{*}{ Creativity } & Innovation and development & \multirow{3}{*}{$\begin{array}{l}\text { The effects on musical rhythmic, logical, } \\
\text { and naturalist intelligences }\end{array}$} \\
\hline & Thinking ability & \\
\hline & Observation ability & \\
\hline \multirow{4}{*}{ Practical ability } & Participation in sports activities & \multirow{4}{*}{$\begin{array}{l}\text { The effects on bodily, logical, intrapersonal } \\
\text { spatial and naturalist intelligences }\end{array}$} \\
\hline & Satisfaction of social service & \\
\hline & Physical function and health & \\
\hline & Teamwork ability & \\
\hline \multirow{8}{*}{ Output } & Pass rate of major courses & \multirow{8}{*}{$\begin{array}{l}\text { The quantified output of students and its } \\
\text { impacts on overall quality }\end{array}$} \\
\hline & Excellent rate of major courses & \\
\hline & Failure rate of major courses & \\
\hline & Participation rate of sports competitions & \\
\hline & Number of sports competition winners & \\
\hline & Number of students engaged in PE research & \\
\hline & $\begin{array}{l}\text { Number of published PE papers authored by } \\
\text { students }\end{array}$ & \\
\hline & $\begin{array}{l}\text { Number of attendees in domes- } \\
\text { tic/international PE academic exchanges }\end{array}$ & \\
\hline
\end{tabular}

\section{$4 \quad$ Evaluation Algorithm}

\subsection{Index processing}

From the above two subsystems, it can be seen that the criterion layer contains two types of indices, namely, benefit indices and cost indices. The quality of a benefit 
index is positively correlated with its value, while that of a cost index is negatively correlated with its value.

To unify the evaluation standard for different perspectives, the two types of indices were normalized as follows. Let $\mathrm{n}$ be the number of evaluation indices, and ${ }^{v_{i}}$ be the value of the i-th evaluation index $r_{i}$ of an object.

\section{Processing of benefit indices}

If a benefit index is qualitative and can be described by fuzzy membership, its value can be expressed as a fuzzy membership function $\psi(r)$ :

$$
v_{i}=\psi\left(r_{i}\right)
$$

If a benefit index is qualitative and can be described by a fuzzy interval number (i.e. the initial value is $\left.u_{i}=\left[u_{i}^{a}, u_{i}^{b}\right], u_{i}^{a} \leq u_{i}^{b}\right)$, its value can be normalized as:

$$
v_{i}=\left[v_{i}^{a}, v_{i}^{b}\right]=\left[\frac{u_{i}^{a}-\inf \left(u_{i}^{a}\right)}{\sup \left(u_{i}^{b}\right)-\inf \left(u_{i}^{a}\right)}, \frac{u_{i}^{b}-\inf \left(u_{i}^{a}\right)}{\sup \left(u_{i}^{b}\right)-\inf \left(u_{i}^{a}\right)}\right], 0 \leq v_{i}^{a} \leq v_{i}^{b} \leq 1
$$

where, $\inf \left(u_{i}^{a}\right)$ and $\sup \left(u_{i}^{b}\right)$ are the lower and upper limits of the i-th evaluation index $r_{i}$, respectively.

If a benefit index is quantitative with an actual value of $u_{i}$, its value can be normalized as:

$$
v_{i}=\frac{u_{i}-\inf \left(u_{i}\right)}{\sup \left(u_{i}\right)-\inf \left(u_{i}\right)}, 0 \leq v_{i} \leq 1
$$

where, $\inf \left(u_{i}\right)$ and $\sup \left(u_{i}\right)$ are the lower and upper limits of the i-th evaluation index $r_{i}$, respectively.

\section{Processing of cost indices}

If a cost index is qualitative and can be described by fuzzy membership, its value can be expressed as a fuzzy membership function $\psi(r)$ :

$$
v_{i}=1-\psi\left(r_{i}\right)
$$

If a cost index is qualitative and can be described by a fuzzy interval number (i.e. the initial value is $\left.u_{i}=\left[u_{i}^{a}, u_{i}^{b}\right], u_{i}^{a} \leq u_{i}^{b}\right)$, its value can be normalized as:

$$
v_{i}=\left[v_{i}^{a}, v_{i}^{b}\right]=\left[\frac{\sup \left(u_{i}^{b}\right)-u_{i}^{b}}{\sup \left(u_{i}^{b}\right)-\inf \left(u_{i}^{a}\right)}, \frac{\sup \left(u_{i}^{b}\right)-u_{i}^{a}}{\sup \left(u_{i}^{b}\right)-\inf \left(u_{i}^{a}\right)}\right], 0 \leq v_{i}^{a} \leq v_{i}^{b} \leq 1
$$


If a benefit index is quantitative with an actual value of $u_{i}$, its value can be normalized as:

$$
v_{i}=\frac{\sup \left(u_{i}\right)-u_{i}}{\sup \left(u_{i}\right)-\inf \left(u_{i}\right)}, 0 \leq v_{i} \leq 1
$$

\subsection{Levels of evaluation indices}

To clarify the evaluation results, the score of each evaluation index was divided into different levels. The number of levels should be controlled in a rational interval. Otherwise, the evaluation results will become vague and fuzzy.

After consulting education experts, scholars and college administrators, the authors decided to divide the score of each evaluation index into seven levels, namely, unacceptable, inadequate, adequate, fair, good, very good and excellent, according to the abovementioned principles. The seven levels constitute a $0-1$ scale, as shown in Table 3 .

Table 3. Levels of evaluation indices

\begin{tabular}{|l|l|c|}
\hline \multicolumn{1}{|c|}{ Levels } & \multicolumn{1}{c|}{ Symbols } & Intervals \\
\hline Unacceptable & $\mathrm{L}_{\mathrm{A}}$ & $0-0.4$ \\
\hline Inadequate & $\mathrm{L}_{\mathrm{B}}$ & $0.4-0.5$ \\
\hline Adequate & $\mathrm{L}_{\mathrm{C}}$ & $0.5-0.6$ \\
\hline Fair & $\mathrm{L}_{\mathrm{D}}$ & $0.6-0.7$ \\
\hline Good & $\mathrm{L}_{\mathrm{E}}$ & $0.7-0.8$ \\
\hline Very good & $\mathrm{L}_{\mathrm{F}}$ & $0.8-0.9$ \\
\hline Excellent & $\mathrm{L}_{\mathrm{G}}$ & $0.9-1.0$ \\
\hline
\end{tabular}

\subsection{Algorithm implementation}

This paper introduces gray clustering analysis to evaluate the learning effect of PE major courses in colleges. Before the gray clustering analysis, the whitening weight function should be set up corresponding to each level of evaluation results. The whitening weight function, the key to the gray clustering analysis, is a continuous function that changes continuously with the independent variable.

The effectiveness of evaluation relies on the following conditions: the whitening weight function must fall on the same level as the membership of the target index; the whitening weight functions corresponding to non-adjacent indices should not intersect each other; there must be a unique point whose membership is one in the whitening weight functions on all seven levels, and the functions on both sides of the point are monotonic.

For these reasons, if the learning effect is unacceptable, the lower limit form of the whitening weight function was adopted (Fig. 1): 


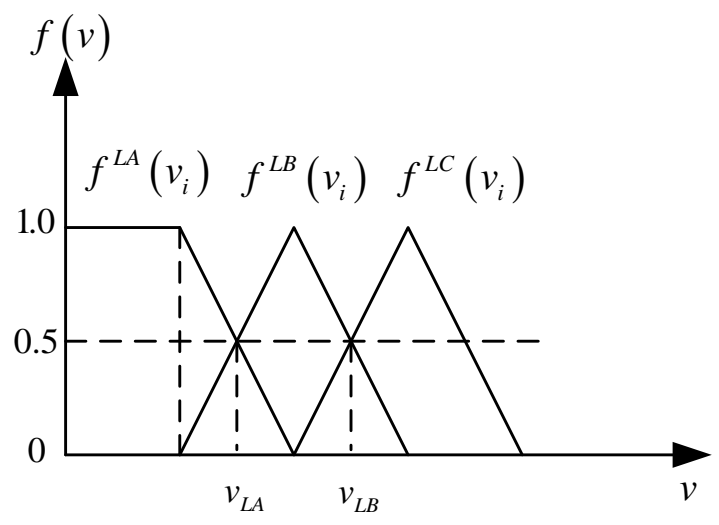

Fig. 1. The lower limit form of the whitening weight function for the unacceptable learning effect

The corresponding calculation model can be expressed as:

$$
f^{L A}\left(v_{i}\right)= \begin{cases}0 & v_{i} \in\left[\frac{v_{L B}+v_{L A}}{2}, 1\right] \\ \frac{v_{L B}+v_{L A}-2 v_{i}}{2\left(v_{L B}-v_{L A}\right)} & v_{i} \in\left[v_{L A}, \frac{v_{L B}+v_{L A}}{2}\right] \\ \frac{1.5 * v_{L A}-v_{i}}{v_{L A}} & v_{i} \in\left[\frac{v_{L A}}{2}, v_{L A}\right] \\ 1 & v_{i} \in\left[0, \frac{v_{L A}}{2}\right]\end{cases}
$$

If the learning effect is excellent, the upper limit form of the whitening weight function was adopted (Fig. 2):

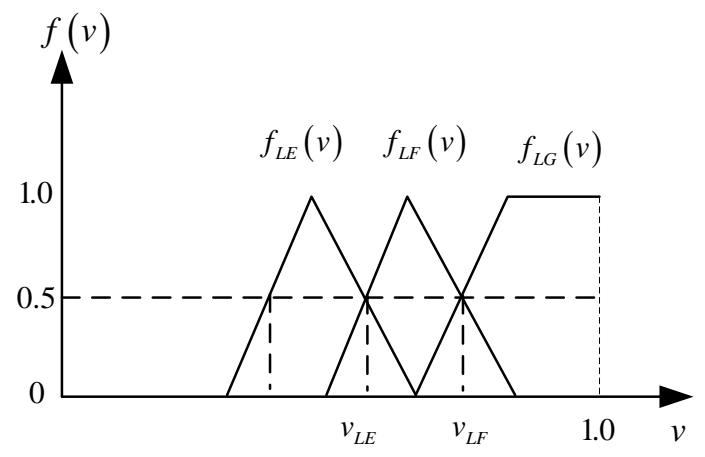

Fig. 2. The upper limit form of the whitening weight function for the excellent learning effect 
The corresponding calculation model can be expressed as:

$$
f^{L G}\left(v_{i}\right)=\left\{\begin{array}{lc}
1 & v_{i} \in\left[\frac{v_{L F}+1}{2}, 1\right] \\
\frac{v_{i}+0.5-1.5 * v_{L F}}{1-v_{L F}} & v_{i} \in\left[v_{L F}, \frac{v_{L F}+1}{2}\right] \\
\frac{v_{i}-0.5 *\left(v_{L F}+v_{L E}\right)}{v_{L F}-v_{L E}} & v_{i} \in\left[\frac{v_{L F}+v_{L E}}{2}, v_{L F}\right] \\
0 & v_{i} \in\left[0, \frac{v_{L F}+v_{L F}}{2}\right]
\end{array}\right.
$$

For learning effects on the other levels $L_{B} \leq L_{j} \leq L_{F}$, the whitening weight function was expressed in triangular form (Fig. 3):

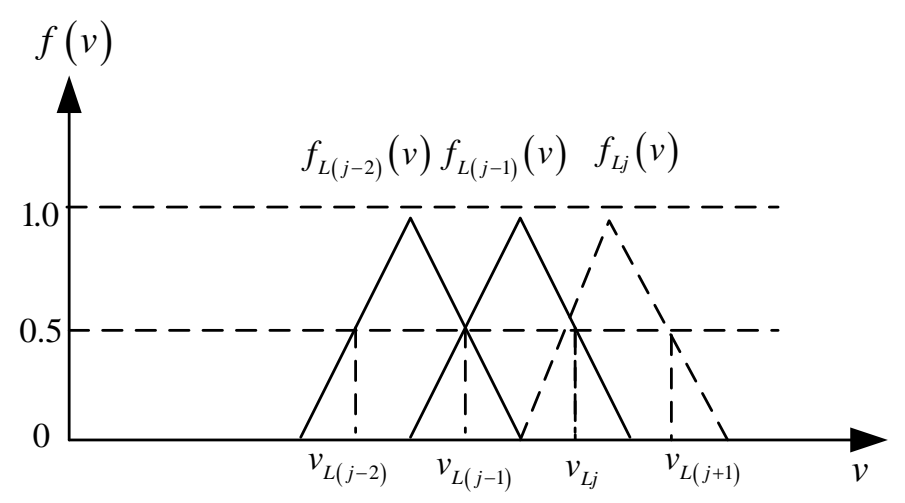

Fig. 3. The triangular form of the whitening weight functions for learning effects on the other levels

The corresponding calculation model can be expressed as: 


$$
f^{L j}\left(v_{i}\right)=\left\{\begin{array}{cc}
\frac{v_{i}-0.5 *\left(v_{L(j-1)}+v_{L(j-2)}\right)}{v_{L(j-1)}-v_{L(j-2)}} & v_{i} \in\left[\frac{v_{L(j-1)}+v_{L(j-2)}}{2}, v_{L(j-1)}\right] \\
\frac{v_{i}+0.5 v_{L j}-1.5 v_{L(j-1)}}{v_{L j}-v_{L(j-1)}} & v_{i} \in\left[v_{L(j-1)} \frac{v_{L j}+v_{L(j-1)}}{2}\right] \\
0 & v_{i} \in\left[0, \frac{\left.v_{L(j-2)}+v_{L(j-1)}\right]}{2}\right] \cup\left[\frac{v_{L j}+v_{L(j+1)}}{2}, 1\right] \\
\frac{1.5 v_{L j}-0.5 v_{L(j-1)}-v_{i}}{v_{L j}-v_{L(j-1)}} & v_{i} \in\left[\frac{v_{L j}+v_{L(j-1)}}{2}, v_{L j}\right] \\
\frac{0.5 *\left(v_{L j}+v_{L(j+1)}\right)-v_{i}}{v_{L(j+1)}-v_{L j}} & v_{i} \in\left[v_{L j}, \frac{v_{L j}+v_{L(j+1)}}{2}\right]
\end{array}\right.
$$

Considering the various index weights and multiple perspectives, the weighted synthetic fuzzy membership of the learning effect can be expressed as:

$$
\phi_{j}=w_{\alpha} * \sum_{i=1}^{n}\left(w_{j} * f_{\alpha}^{L j}\left(v_{i}\right)\right)+w_{\beta} * \sum_{i=1}^{n}\left(w_{j} * f_{\beta}^{L j}\left(v_{i}\right)\right)
$$

where, $w_{\alpha}$ and $w_{\beta}$ are the weights from the perspectives of teachers and students, respectively; $f_{\alpha}^{L j}\left(v_{i}\right)$ and $f_{\beta}^{L j}\left(v_{i}\right)$ are the fuzzy memberships when the index membership falls on level $L j$ from the perspectives of teachers and students, respectively.

Formula (10) provides the weighted synthetic fuzzy membership of each object, which determines the evaluation level of the object.

\section{Conclusion}

This paper firstly analyzes the problems in learning effect evaluation of PE major courses in colleges, and puts forward the principles for index selection. Drawing on multiple intelligence theory, an evaluation index system for the said learning effect was established from the perspectives of teachers and students. Then, a fuzzy evaluation algorithm was developed based on the gray clustering analysis, aiming to effectively quantify the learning effect. The proposed evaluation model involves both theoretical innovation and algorithm implementation, providing a highly operable and feasible method for evaluation of complex systems.

\section{References}

[1] Király, G., \& Géring, Z. (2019). Introduction to 'Futures of Higher Education' special issue. Futures, 111: 123-129. https://doi.org/10.1016/j.futures.2019.03.004 
[2] Srivastava, A. P., Mani, V., \& Yadav, M. (2019). Evaluating the implications of stakeholder's role towards sustainability of higher education. Journal of Cleaner Production, 240: 1-10. https://doi.org/10.1016/j.jclepro.2019.118270

[3] Pan, L. (2019). A big data-based data mining tool for physical education and technical and tactical analysis. International Journal of Emerging Technologies in Learning, 14(22): 220231. https://doi.org/10.3991/ijet.v14i22.11345

[4] Rourke, S. (2019). How does virtual reality simulation compare to simulated practice in the acquisition of clinical psychomotor skills for pre-registration student nurses? A systematic review. International Journal of Nursing Studies, 102: 1-7. https://doi.org/10. 1016/j.ijnurstu.2019.103466

[5] Zhao, Z., Yang, J. (2019). Design and implementation of computer aided physical education platform based on Browser/Server architecture. International Journal of Emerging Technologies in Learning, 14(15): 40-51. https://doi.org/10.3991/ijet.v14i15. $\underline{11146}$

[6] Santoso, L. W. (2017). Data warehouse with big data technology for higher education. Procedia Computer Science, 124: 93-99. https://doi.org/10.1016/j.procs.2017. $\underline{12.134}$

[7] Kwon, E. H., \& Block, M. E. (2017). Implementing the adapted physical education Elearning program into physical education teacher education program. Research in Developmental Disabilities, 69: 18-29. https://doi.org/10.1016/j.ridd.2017.07.001

[8] Egan, C. A., Webster, C. A., Stewart, G. L., Weaver, R. G., Russ, L. B., Brian, A., \& Stodden, D. F. (2019). Case study of a health optimizing physical education-based comprehensive school physical activity program. Evaluation and Program Planning, 72: 106117. https://doi.org/10.1016/j.evalprogplan.2018.10.006

[9] Packham, A., \& Street, B. (2019). The effects of physical education on student fitness, achievement, and behavior. Economics of Education Review, 72: 118.https://doi.org/10.1016/j.econedurev.2019.04.003

[10] Heemskerk, C. H. H. M., Lubans, D., Strand, S., \& Malmberg, L. E. (2019). The effect of physical education lesson intensity and cognitive demand on subsequent learning behaviour. Journal of Science and Medicine in Sport, 1-5. https://doi.org/10. 1016/j.jsams.2019.12.012

[11] Yan, Y. (2019). Design and Implementation of a Teaching Assistance Platform for College Students Based on ASP.NET. International Journal of Emerging Technologies in Learning, 14(12): 97-108. https://doi.org/10.3991/ijet.v14i12.10707

[12] Zeng, Y.S. (2020). Evaluation of physical education teaching quality in colleges based on the hybrid technology of data mining and hidden Markov model. International Journal of Emerging Technologies in Learning, 15(1): 4-15. https://doi.org/10.3991/ijet. $\underline{\mathrm{v} 15 \mathrm{i} 01.12533}$

[13] Khan, A. A., Shameem, M., Kumar, R. R., Hussain, S., \& Yan, X. (2019). Fuzzy AHP based prioritization and taxonomy of software process improvement success factors in global software development. Applied Soft Computing, 83: 1-24. https://doi.org/10. 1016/j.asoc.2019.105648

[14] Xie, Z.L., Yin, H.K. (2018). Selection of optimal cloud services based on quality of service ontology. Ingénierie des Systèmes d'Information, 23(6): 127-141. https://doi.org/10. 3166/isi.23.6.127-141

[15] Akben, S. B. (2018). Predicting the success of wart treatment methods using decision tree based fuzzy informative images. Biocybernetics and Biomedical Engineering, 38(4): 819827. https://doi.org/10.1016/j.bbe.2018.06.007 
[16] Teki, S.M., Banothu, B., Varma, M.K. (2019). An un-realized algorithm for effective privacy preservation using classification and regression trees. Revue d'Intelligence Artificielle, 33(4): 313-319. https://doi.org/10.18280/ria.330408

[17] Wang, L. (2019). Computing the estimator of a parameter vector via a competing Bayes method. Mathematics and Computers in Simulation, 165: 271-279. https://doi.org/10. 1016/j.matcom.2019.03.011

[18] Evangelou, E., \& Maroulas, V. (2017). Sequential empirical Bayes method for filtering dynamic spatiotemporal processes. Spatial Statistics, 21: 114-129. https://doi.org/10. 1016/j.spasta.2017.06.006

[19] Ghiasi, A., Hussain, O., Qian, Z. S., \& Li, X. (2017). A mixed traffic capacity analysis and lane management model for connected automated vehicles: A Markov chain method. Transportation Research Part B: Methodological, 106: 266-292. https://doi.org/10. 1016/j.trb.2017.09.022

[20] Xing, R.F., Fan, Y.Y., Liu, W. (2019). A Markov chain-based overlapping community detection algorithm for complex networks. Ingénierie des Systèmes d'Information, 24(6): 577-582. https://doi.org/10.18280/isi.240603

[21] Shearer, C. B., \& Karanian, J. M. (2017). The neuroscience of intelligence: Empirical support for the theory of multiple intelligences? Trends in neuroscience and education, 6: 211223. https://doi.org/10.1016/j.tine.2017.02.002

[22] Kılıç, M. S., \& Sert, H. (2015). Primary school 5th grade science and technology lesson book's investigation of multiple intelligence theory. Procedia-Social and Behavioral Sciences, 174: 2577-2581. https://doi.org/10.1016/j.sbspro.2015.01.935

[23] Tezer, M., Ozturka, R., \& Ozturkb, C. (2015). A case study on the effect of geometry course in high schools by multiple intelligence theory. Procedia-Social and Behavioral Sciences, 197: 31-37. https://doi.org/10.1016/j.sbspro.2015.07.044

[24] Javed, S. A., Mahmoudi, A., Khan, A. M., Javed, S., \& Liu, S. (2018). A critical review: shape optimization of welded plate heat exchangers based on grey correlation theory. Applied Thermal Engineering, 144: 593-599. https://doi.org/10.1016/j.applthermaleng. $\underline{2018.08 .086}$

[25] Bezuglov, A., \& Comert, G. (2016). Short-term freeway traffic parameter prediction: Application of grey system theory models. Expert Systems with Applications, 62: 284292.https://doi.org/10.1016/j.eswa.2016.06.032

[26] Lee, C., Lee, J. W., Ryu, S. G., \& Oh, J. H. (2019). Optimum design of a large area, flexure based XY $\theta$ mask alignment stage for a 12 -inch wafer using grey relation analysis. Robotics and Computer-Integrated Manufacturing, 58: 109-119. https://doi.org/10. 1016/j.rcim.2019.02.005

[27] Karakoç, Ö., Es, H. A., \& Firat, S. Ü. (2019). Evaluation of the development level of provinces by grey cluster analysis. Procedia Computer Science, 158: 135144.https://doi.org/10.1016/j.procs.2019.09.036

\section{$7 \quad$ Author}

Shimin Tong is working as College of Physical Education, Chongqing Technology and Business University, Chongqing 400067, China, with the research interest in Physical Education and Training. Email: 619875667@qq.com

Article submitted 2020-02-11. Resubmitted 2020-03-14. Final acceptance 2020-03-14. Final version published as submitted by the authors. 